\title{
EDUCATION
}

\section{Professional Development of Teachers in Europe}

\author{
Nikos Kougkas \\ 5th Primary School of Evosmos, Thessaloniki, Greece
}

\begin{abstract}
The configuration of teachers with a high level of professionalism, their proper preparation for the profession and their appropriate training support, are today a common goal for all countries of the European Union. Nowadays more than ever, the role of the teacher is so close to the role of the student, as teachers teach and at the same time are taught in a continuous environment of professional development. The changes in education are due to the general social and economic reorganizations that are taking place worldwide. The meaning of teacher's development is found in their personal and professional lives, as well as in the school environments in which they work, since the nature of their profession requires to be committed to the direction of their professional development during their careers. However, teachers are not required to participate in all European countries and their non-participation has no negative consequences. Even in countries where it is compulsory, the participation rate is not necessarily high, while at the same time in other places the in-service training is only a factor that affects career development and increase teachers' salaries. The lack of associate teachers and the cost of the training programs are a disincentive to participate in them in many countries, as there is nowhere a special budget for teachers to take part in training activities.
\end{abstract}

Keywords: changes; education; participation; school; students 